\title{
Rheumatoid arthritis patients exhibit impaired Candida albicans-specific Th17 responses
}

Shrinivas Bishu', Ee Wern Su², Erich R Wilkerson², Kelly A Reckley², Donald M Jones², Mandy J McGeachy², Sarah L Gaffen ${ }^{2^{*}}$ and Marc C Levesque ${ }^{2^{*}}$

\begin{abstract}
Introduction: Accumulating data implicate the CD4+ T cell subset (Th17 cells) in rheumatoid arthritis (RA). IL-17 is an inflammatory cytokine that induces tumor necrosis factor (TNF)a, IL-1 $\beta$ and IL-6, all of which are targets of biologic therapies used to treat RA. RA patients are well documented to experience more infections than age-matched controls, and biologic therapies further increase the risk of infection. The Th17/IL-17 axis is vital for immunity to fungi, especially the commensal fungus Candida albicans. Therefore, we were prompted to examine the relationship between RA and susceptibility to C. albicans because of the increasing interest in Th17 cells and IL-17 in driving autoimmunity, and the advent of new biologics that target this pathway.
\end{abstract}

Methods: We analyzed peripheral blood and saliva from 48 RA and 33 healthy control subjects. To assess C. albicans-specific Th17 responses, PBMCs were co-cultured with heat-killed C. albicans extract, and IL-17A levels in conditioned supernatants were measured by ELISA. The frequency of Th17 and Th1 cells was determined by flow cytometry. As a measure of IL-17A-mediated effector responses, we evaluated C. albicans colonization rates in the oral cavity, salivary fungicidal activity and levels of the antimicrobial peptide $\beta$-defensin 2 (BD2) in saliva.

Results: Compared to controls, PBMCs from RA subjects exhibited elevated baseline production of IL-17A ( $P=0.004)$, although they had similar capacity to produce IL-17A in response to Th17 cell differentiating cytokines $(P=0.91)$. However RA PBMCs secreted less IL-17A in response to $C$. albicans antigens $(P=0.006)$. Significantly more RA patients were colonized with $C$. albicans in the oral cavity than healthy subjects $(P=0.02)$. Concomitantly, RA saliva had reduced concentrations of salivary BD2 $(P=0.02)$. Nonetheless, salivary fungicidal activity was preserved in RA subjects $(P=0.70)$.

Conclusions: RA subjects exhibit detectable impairments in oral immune responses to C. albicans, a strongly Th17-dependent opportunistic pathogen, despite an overall elevated baseline production of IL-17A.

\section{Introduction}

Rheumatoid arthritis (RA) is a chronic autoimmune disease characterized by symmetric polyarthritis and systemic inflammation. Accumulating evidence implicates the cytokine interleukin (IL)-17 and $\mathrm{CD} 4^{+}$T-helper type (Th)17 cells in the pathogenesis of RA [1,2]. IL-17 is a proinflammatory cytokine that both induces and synergizes with tumor necrosis factor (TNF) alpha to promote induction of IL- $1 \beta$ and IL- 6 in target cells, culminating in the production of factors such as matrix metalloproteinases and reactive oxygen species that drive erosive arthritis [3].

\footnotetext{
* Correspondence: sig65@pitt.edu; marclevesque01581@gmail.com ${ }^{2}$ Division of Rheumatology \& Clinical Immunology, Department of Medicine, University of Pittsburgh, BST S702, 3500 Terrace Street, Pittsburgh, PA 15261, USA

Full list of author information is available at the end of the article
}

Consistent with the role of the Th17/IL-17 axis in the pathogenesis of RA, patients with severe disease exhibit elevated frequencies of Th17 cells, and clinical responses to TNF $\alpha$ inhibitors in autoimmune subjects have been associated with reductions in circulating Th17 cells $[4,5]$.

Whereas heightened immune responses are pathogenic, RA is paradoxically associated with impaired host defense to microbes. Epidemiologic studies have consistently demonstrated a higher incidence of infection in RA patients compared with the normal population, even when the effects of medications are controlled for [6,7]. The modern era of targeted anti-cytokine therapies has resulted in prolonged steroid-free remissions. To some extent, however, this remission has come at the cost of increased susceptibility to opportunistic pathogens, highlighting the importance of these cytokines in host defense. Antibodies against 
IL-17 or its receptor IL-17RA have shown promise in early clinical trials for several autoimmune conditions including RA, but their potential impact on susceptibility to infection is poorly defined [8-12].

Candida albicans is a commensal fungus that colonizes mucocutaneous surfaces including the oral cavity, tracheobronchial tree and gastrointestinal and genitourinary tracts. The Th17/IL-17A axis is essential for protective immunity to mucocutaneous candidiasis [13], and most Candida-responsive $\mathrm{T}$ cells are of the Th17 phenotype [14]. Humans with impaired induction of Th17 cells (for example, mutations in STAT1, STAT3 or CARD9) or defects in IL-17A signaling (for example, mutations in IL17RA or IL17F) are highly susceptible to chronic mucocutaneous candidiasis - a condition also seen in patients with circulating antibodies against Th17 cytokines, such as in autoimmune polyendocrinopathy syndrome-1 or certain thymomas $[15,16]$. Somewhat surprisingly, Candida infections are not widely reported in RA [17]; however, recent epidemiologic data from patients with inflammatory bowel disease demonstrate that TNF $\alpha$ inhibitors increase the risk of oropharyngeal candidiasis (OPC) at rates similar to mycobacterial infections [18]. Furthermore, the emerging use of biologics targeting Th17 pathways is likely to increase the incidence of $C$. albicans and other fungal infections $[9,19]$.

Despite the known susceptibility of RA patients to infections, there is surprisingly limited information on pathogen-specific host responses in RA, especially to fungi. Furthermore, many biologics target Th17 cell generation or effector function, and yet the functional impact of RA medications on IL-17-dependent host defense is poorly understood. We therefore sought to evaluate the impact of RA on Th17 responses to C. albicans.

\section{Methods}

\section{Subjects}

RA subjects $(n=48)$ and healthy controls $(n=33)$ were recruited from the University of Pittsburgh Rheumatoid Arthritis Comparative Effectiveness Research Registry. Clinical and demographic data were then extracted from the Registry. The University of Pittsburgh institutional review board approved this study and all subjects provided written informed consent.

\section{Peripheral blood mononuclear cell cultures}

Peripheral blood mononuclear cells (PBMCs) were isolated from whole blood using Lymphocyte Separation Media (Accurate Chemical and Scientific, Westbury, NY, USA) and buoyant density centrifugation. PMBC stimulation was performed by seeding 48-well, flat-bottom, cell culture plates with 500,000 PBMCs $\pm 1 \times 10^{6}$ heatkilled (HK) C. albicans (prepared by boiling $\sim 4 \times 10^{8} \mathrm{C}$. albicans cells for 45 minutes) or a Th17 differentiating cocktail of recombinant human IL-1 $\beta(10 \mathrm{ng} / \mathrm{ml})$, recombinant human IL-6 (50 ng/ml), recombinant human IL-23 $(20 \mathrm{ng} / \mathrm{ml})$, recombinant human transforming growth factor beta (TGF $\beta ; 10 \mathrm{ng} / \mathrm{ml})$, recombinant human IL-2 (24 IU/ml), anti-IL-12 $(5 \mu \mathrm{g} / \mathrm{ml})$ and anti-IL-4 (5 $\mu \mathrm{g} / \mathrm{ml})$ (R\&D Systems, Minneapolis MN, USA) [20]. Supernatants were collected after 5 days and were analyzed in triplicate for IL-17A by enzyme-linked immunosorbent assay (eBiosciences, San Diego, CA, USA). C. albicans was prepared by culturing strain CAF2-1 in yeast peptone dextrose at $30^{\circ} \mathrm{C}$ overnight with agitation.

\section{Intracellular cytokine staining and flow cytometry}

PBMCs were rested overnight in RPMI supplemented with $10 \%$ fetal bovine serum, L-glutamine, non-essential amino acids, sodium pyruvate, penicillin and streptomycin; $1 \times 10^{6}$ PBMCs were then stimulated for 4 hours with $50 \mathrm{ng} / \mathrm{ml}$ phorbol 12-myristate 13-acetate and $1 \mu \mathrm{g} / \mathrm{ml}$ ionomycin in the presence of Golgi Plug (BD Biosciences, Franklin Lakes, NJ, USA). Following stimulation, cells were stained with anti-CD3 Violet 450 (clone UCHT1), antiCD4 Per CP Cy 5.5 (clone OKT4), anti-CD45RO APC-H7 (clone UCHL1), anti-CD161 PE (clone DX12), anti-CD8 FITC (clone RPA-T8), interferon gamma (IFNY) V500 (clone B27) and anti-IL-17A APC (clone N49-653). Intracellular cytokine staining was performed with the Cytofix Cytoperm kit (BD Biosciences). Data were acquired on a BD Aria II (BD Biosciences) and were analyzed with FlowJo (Ashland, OR, USA).

\section{Salivary assays}

Saliva samples were collected by expectoration and placed in a 10x protease inhibitor cocktail (cocktail set III; Calbiochem/EMD, Gibbstown, NJ, USA), and saliva was centrifuged for 5 minutes at $550 \times \mathrm{g}$. Baseline oral C. albicans carriage was determined by plating the supernatant fraction of spun saliva in triplicate on yeast peptone dextrose plates with antibiotics (to suppress growth of oral bacteria) and $C$. albicans colony enumeration after incubation at $30^{\circ} \mathrm{C}$ for 48 hours. Salivary C. albicans killing was determined by incubating the salivary supernatant at $37^{\circ} \mathrm{C}$ with $1 \times 10^{6} \mathrm{C}$. albicans cells (strain CAF2-1) (1:1, v/v) for 1 hour [21]. C. albicans cells were plated in triplicate for colony enumeration. For $\beta$-defensin 2 (BD2) assessment, the supernatant was analyzed using a BD2 enzyme-linked immunosorbent assay kit in duplicate or triplicate as volume allowed (Phoenix Pharmaceuticals, Burlingame, CA, USA). $\mathrm{BD} 2$ concentrations were normalized to the total protein content of centrifuged saliva, which was measured by the bicinchoninic acid assay (BioRad, Hercules, CA, USA).

\section{Statistical analysis}

Tests for normality and variance were performed on all datasets, and two-tailed Student's $t$ tests or nonparametric 
Wilcoxon rank-sum tests were applied as indicated. Paired Student's $t$ tests were used to assess paired samples, and Fischer's exact test was used to assess categorical variables. Correlations were examined using Spearman's correlation coefficient. GraphPad Prism 4.0 was used for all statistical analyses (GraphPad, La Jolla, CA, USA).

\section{Results}

T cells from RA patients exhibit impaired Candida albicans-specific IL-17A responses

We analyzed peripheral blood samples and saliva from 48 RA subjects and 23 healthy control subjects. Demographic and clinical characteristics of the subjects are described in Table 1. All RA subjects were receiving oral disease-modifying anti-rheumatic drugs (DMARDs) and/or biologic therapy (primarily TNFo antagonists), with $17 \%$ on biologic monotherapy, $44 \%$ on oral DMARDs only and $38 \%$ receiving combination therapy. The majority of RA subjects (75\%) were in remission or had low disease activity with a 28 -joint Disease Activity Score $<3.1$.

To evaluate the impact of RA on specific responses to C. albicans, we co-cultured fresh PBMCs from RA subjects or healthy controls with $1 \times 10^{6} \mathrm{HK} C$. albicans for 5 days. As controls, PBMCs from the same subjects were cultured in media alone (to monitor basal IL-17A production) or with a cocktail of Th17 differentiating cytokines (IL-1 $\beta$, IL-6, IL-23, anti-IL-4 and anti-IFNY). RA subjects exhibited higher basal IL-17A production $(31.5 \mathrm{pg} / \mathrm{ml}$, range: 0 to 146.9 ) than healthy controls (where it was not detectable) $(P=0.02)$. During co-culture with Th17 differentiating cytokines, PBMCs from RA subjects and healthy controls produced similar amounts of IL-17A (mean: $159.6 \mathrm{pg} / \mathrm{ml}$, range: 0 to 636.3 vs. mean: $166.8 \mathrm{pg} / \mathrm{ml}$, range: 33.7 to $596.4 ; P=0.91$ ). In contrast, upon coculture with $\mathrm{HK} C$. albicans, PBMCs from RA subjects produced significantly lower IL-17A than control PBMCs

Table 1 Patient characteristics

\begin{tabular}{lcc}
\hline & $\begin{array}{c}\text { Rheumatoid } \\
\text { arthritis patients }\end{array}$ & $\begin{array}{c}\text { Healthy } \\
\text { controls }\end{array}$ \\
\hline Number & 48 & 33 \\
Age & $56 \pm 13$ & $43 \pm 13$ \\
$\%$ female & 75 & 43 \\
Disease duration (years) & $12 \pm 10$ & - \\
Cyclic citrullinated & $232 \pm 397$ & - \\
peptide lgG (units) & $133 \pm 236$ & - \\
Rheumatoid factor (IU/ml) & $1 \pm 1.75$ & - \\
C-reactive protein (mg/dl) & $3.1 \pm 1.5$ & - \\
Disease activity score & $92 \%$ & - \\
DMARDs (\%) & $54 \%$ & - \\
TNFa inhibitors (\%) & $23 \%$ & - \\
Prednisone (\%) & & \\
\hline DMARD, disease-modifyng anti-rheumatic & & - \\
\hline
\end{tabular}

DMARD, disease-modifying anti-rheumatic drug; TNF, tumor necrosis factor. (mean: $259.2 \mathrm{pg} / \mathrm{ml}$, range: 0 to 798.9 vs. mean: $508.1 \mathrm{pg} / \mathrm{ml}$, range: 34.8 to $925 ; P=0.006$ ) (Figure $1 \mathrm{~A}$ ). In RA subjects, levels of IL-17A from the basal PBMC cultures correlated with IL-17A levels from the Th17 differentiating cocktail cultures $(r=0.57, P=0.003$; Additional file 1: Figure S1A). Therefore, despite higher basal IL-17A and a preserved capacity to respond to Th17 differentiating cytokines, $\mathrm{CD}_{4}^{+}$cells from RA subjects exhibited impaired C. albicans-specific Th17 responses, at least as measured in vitro.

To address the possibility that oral DMARDs and biologics caused altered C. albicans-specific responses, we stratified the analyses of IL-17A production and Th17 and Th1 frequencies by medication usage in the RA cohort. As shown in Figure 1B, there were no detectable differences in the capability of PBMCs from RA subjects treated with different classes of medications to produce IL-17A under different stimulation conditions (media alone, HK C. albicans or Th17 differentiation cocktail). Similarly, there were no significant differences in Th17 or Th1 cell frequencies in peripheral blood from RA subjects treated with oral DMARDs alone, biologics alone or combinations of oral DMARDs and biologics (Figure 1C). Biologics therefore do not exacerbate the Candidaspecific impairments in DMARD-treated patients.

\section{Rheumatoid arthritis subjects have lower proportions of Th17 cells compared with healthy controls}

Th17 cells are necessary to prevent OPC, as revealed by a variety of genetic syndromes associated with chronic mucocutaneous candidiasis [15]. To determine whether the impaired C. albicans-specific response was due to a reduced frequency of total circulating Th17 cells, we compared the frequencies of IL-17A ${ }^{+}$(Th17 cells) and IFN $\gamma^{+}$ (Th1) $\mathrm{CD}^{+} \mathrm{T}$ cells in peripheral blood. RA subjects exhibited a slightly reduced percentage of Th17 cells compared with controls $(0.50 \pm 0.05 \%$ and $0.67 \pm 0.07 \%$, respectively; $P=0.02$ ), and a higher percentage of Th1 cells $(17.33 \pm 1.5 \%$ vs. $9.85 \pm 1.1 \% ; P=0.002)$ (Figure $2 \mathrm{~A}$ ).

The majority of Th17 cells in healthy individuals reside in the $\mathrm{CD} 161^{+}$and effector memory $\left(\mathrm{T}_{\mathrm{EM}}, \mathrm{CD} 45 \mathrm{RO}^{+} \mathrm{CCR} 7^{-}\right)$ compartments, which we confirmed in this study (data not shown). We first looked at total $\mathrm{CD} 161^{+}$and $\mathrm{T}_{\mathrm{EM}}$ cells, and found no difference in the frequencies of these populations between healthy and RA subjects (Figure 2B; $P=0.82$ and $P=0.36$, respectively). We then looked at frequencies of T-effector subsets within these populations. Both RA subjects and healthy controls showed similar frequencies of Th17 or Th1 cells in the CD161 $1^{+}$compartment (respectively $1.44 \pm 0.55 \%$ vs. $1.33 \pm 0.11 \% ; P=0.11$; $13.81 \pm 1.48 \%$ versus $12.79 \pm 1.64 \% ; P=0.66$ ) (Figure $2 C$ ). There were also no differences in the relative distributions of Th17 or Th1 cells in the $\mathrm{T}_{\mathrm{EM}}$ compartment (respectively $1.21 \pm 0.20 \%$ vs. $0.98 \pm 0.09 \% ; P=0.32$; 


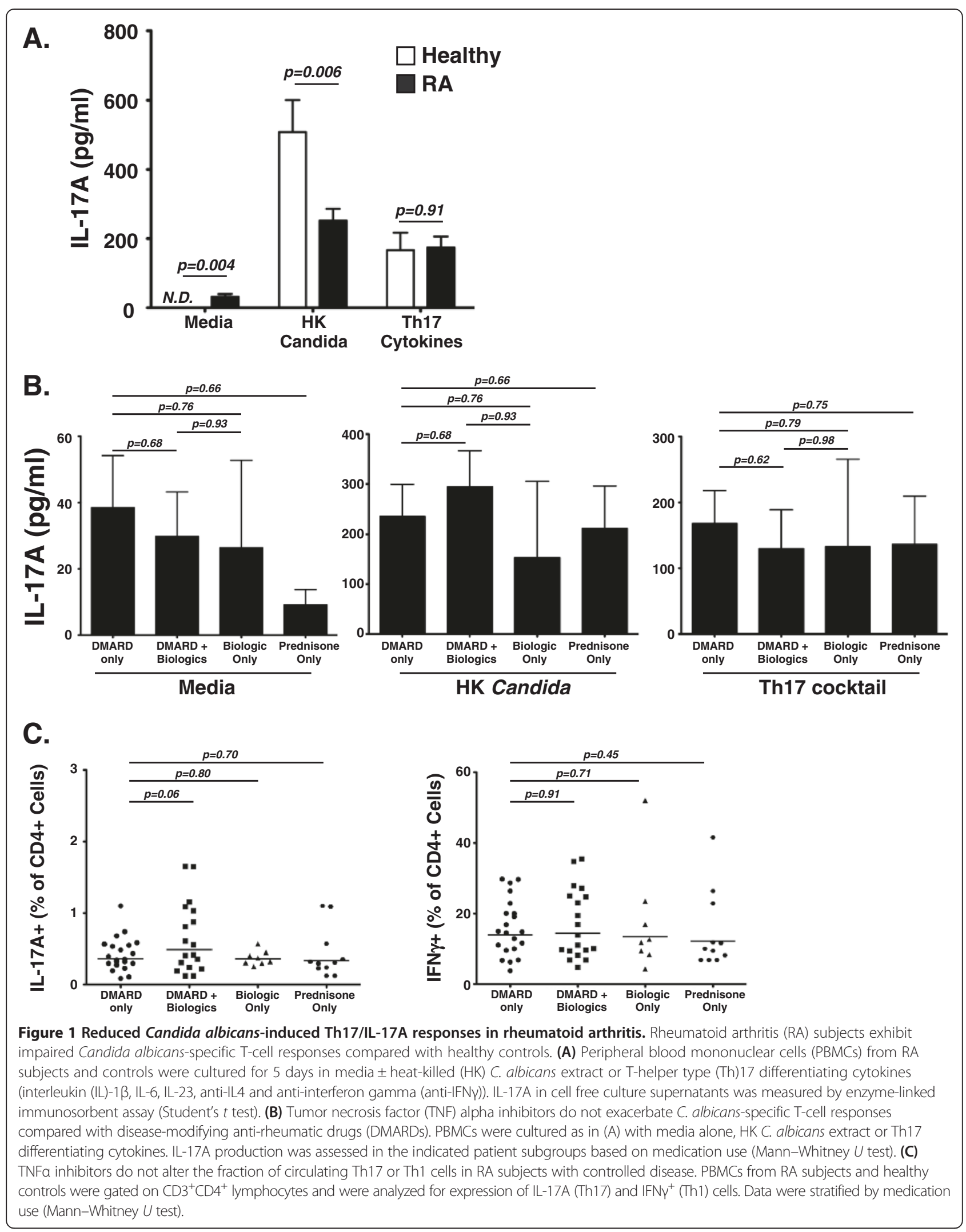


A.

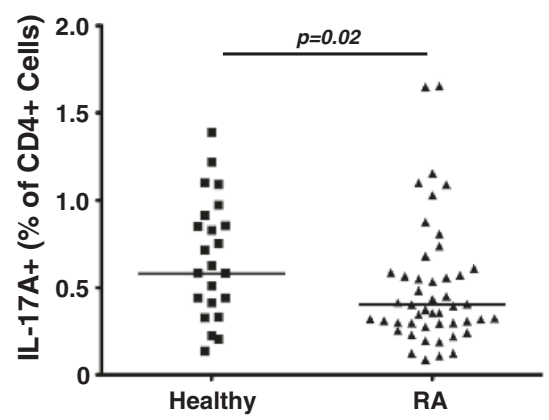

B.
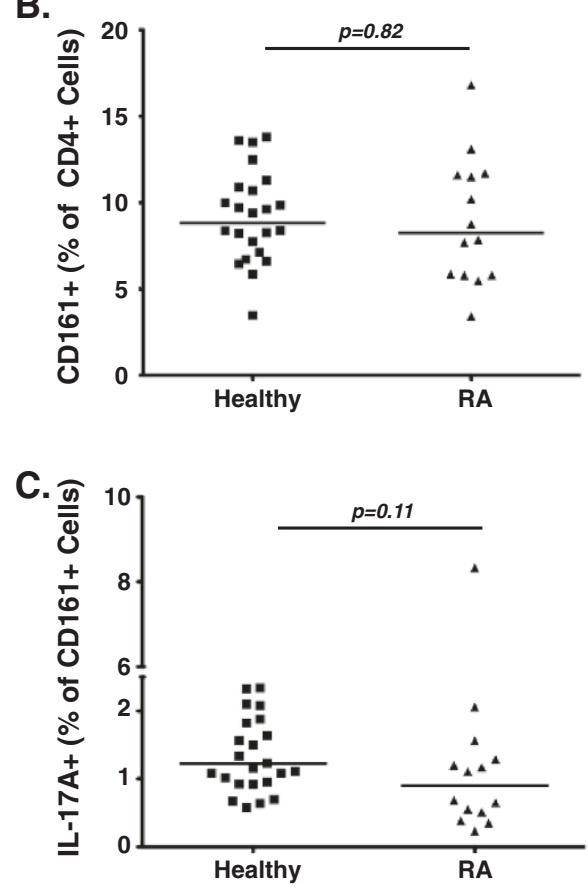

D.

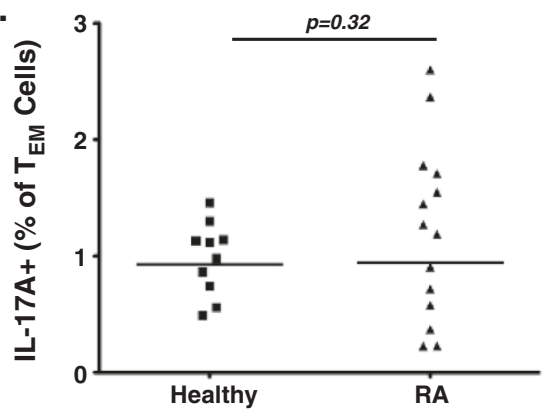

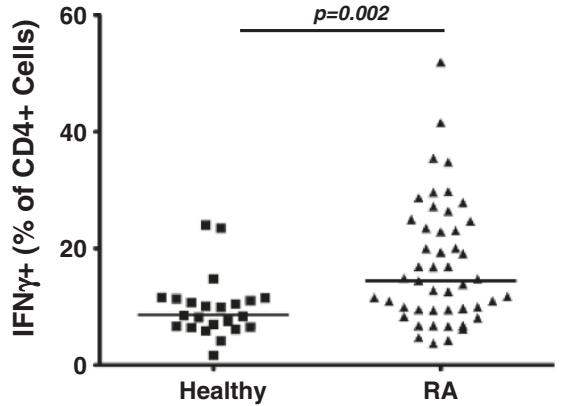
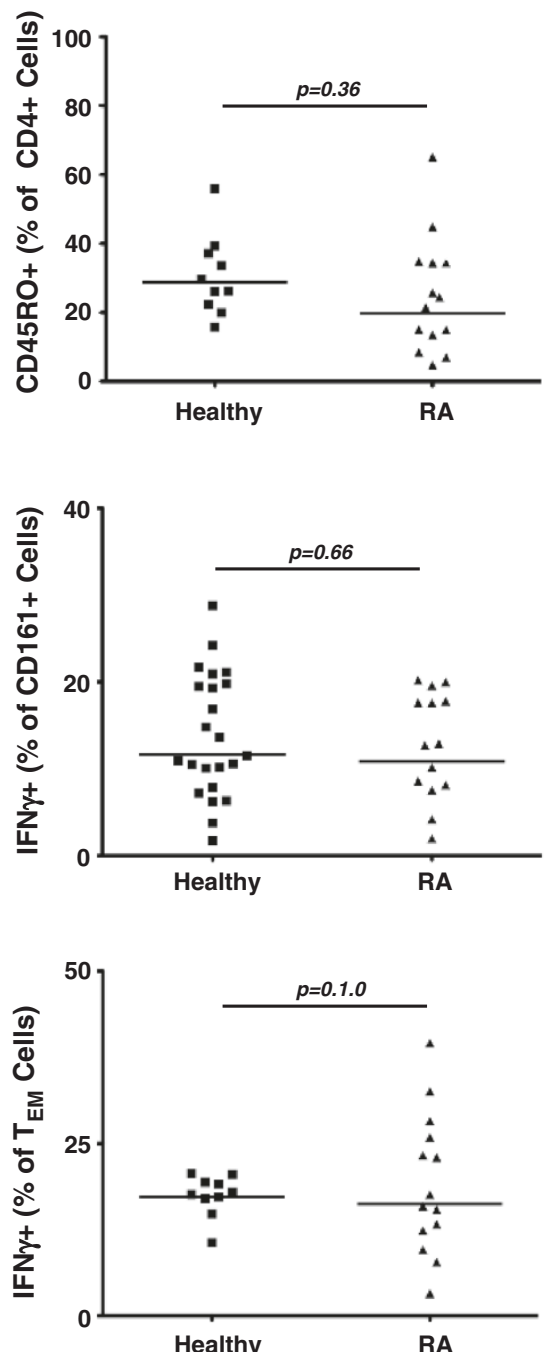

Figure 2 Rheumatoid arthritis subjects have a lower proportion of IL-17 ${ }^{+}$but a higher proportion of IFN $\gamma^{+} \mathrm{CD} 4^{+} \mathrm{T}_{\text {cells }}$ compared with controls. (A) Circulating T-helper type (Th)17 and Th1 cells. Peripheral blood mononuclear cells (PBMCs) from rheumatoid arthritis (RA) patients and healthy controls were gated on $\mathrm{CD}^{+} \mathrm{CD}^{+}$lymphocytes and were analyzed for expression of interleukin (IL)-17A (Th17 cells) and interferon gamma (IFNY; Th1 cells) (Mann-Whitney $U$ test). (B) Circulating $C D 161^{+}$and $T_{E M}$ Cells. PBMCs were gated on $C D 3^{+} C D 4^{+}$lymphocytes and were analyzed for expression of CD161 and CD45RO (TEM Cells) (Mann-Whitney $U$ test). (C) CD161 ${ }^{+} I L 17 A^{+}$population. PBMCs were gated on $\mathrm{CD}^{+} \mathrm{CD}^{+} \mathrm{CD} 161^{+}$and analyzed for expression of IL-17A and IFNy (Mann-Whitney $U$ test). (D) $\mathrm{T}_{\mathrm{EM}} \mathrm{IL}-17 \mathrm{~A}^{+}$population. PBMCs were gated on $\mathrm{CD}^{+} \mathrm{CD}^{+} \mathrm{CD} 45 \mathrm{RO}^{+}$lymphocytes and were analyzed for expression of IL-17A and IFNY (Mann-Whitney $U$ test). 
$17.49 \pm 0.94 \%$ vs. $19.14 \pm 2.7 \% ; P=1)$. As expected, there was a significant correlation between the frequency of circulating Th17 cells and IL-17A production during PBMC co-culture with HK C. albicans $(r=0.412, P=0.04)$ (Additional file 1: Figure S1B). Accordingly, the impaired in vitro and in vivo pathogen-specific responses in RA subjects were associated with reductions in total circulating Th17 cells.

\section{Rheumatoid arthritis patients exhibit reduced IL-17A- dependent anti-Candida effector responses in the oral cavity}

In the oral mucosa, IL-17A induces antimicrobial proteins (AMPs) such as BD2 and salivary histatins, which are central mediators of host defense against C. albicans [22]. Sjögren's syndrome patients and others with salivary defects are prone to OPC [23]. We previously reported that Job's syndrome patients, who are Th17-deficient due to mutations in STAT3, exhibit enhanced oral colonization with $C$. albicans and concordantly reduced $C$. albicans killing capacity and salivary BD2 concentrations [21]. Accordingly, we sought to determine whether anti-Candida effector responses such as AMP expression in saliva were impacted in RA subjects. As shown, RA subjects were more likely to be colonized with $C$. albicans in the oral cavity than healthy controls $(50 \%$ vs. $15 \% ; P=0.02)$ (Figure 3A). The number of $C$. albicans organisms detected in saliva was not statistically different between healthy and RA subjects $(P=0.53$; Figure $3 \mathrm{~B})$, with some healthy individuals showing quite high colonization of this commensal microbe. However, RA subjects exhibited significantly lower concentrations of salivary BD2 than healthy controls ( $1.3 \pm 0.18$ vs. $2.2 \pm 0.42 ; P=0.02$ ) (Figure $3 C$ ). There was no evident correlation between Candida colonization and BD2 levels (data not shown). To determine whether reduced BD2 levels were associated with a functional deficit in antifungal immunity, saliva samples were co-incubated in vitro with a constant number of cells from a reference strain of C. albicans, and survival of the fungus was assessed relative to a PBS control. As shown in Figure 3D, salivary killing activity was similar between RA subjects and healthy controls $(P=0.70)$. Thus, while there were increased colonization rates of Candida and reduced IL-17A-dependent salivary AMPs, salivary candidacidal function appeared to be preserved in RA subjects, which is consistent with their clinical resistance to OPC.
A.

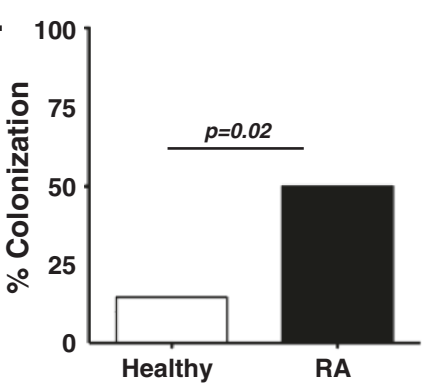

C.

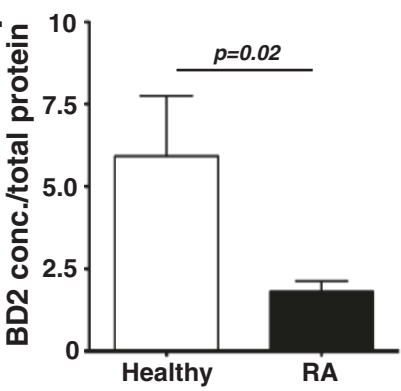

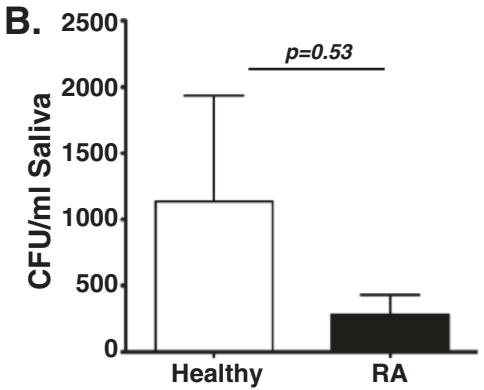

D.

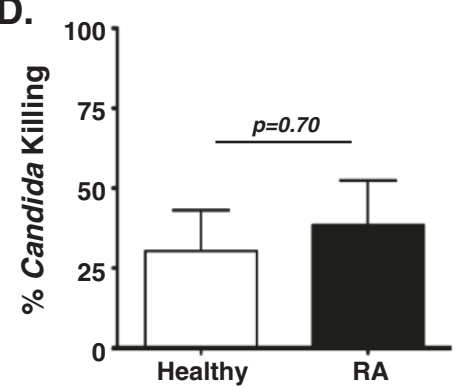

Figure 3 Rheumatoid arthritis subjects have impaired IL-17A-dependent anti-microbial peptide induction, but preserved oral immunity to Candida albicans. (A), (B) Candida albicans colonization in the oral cavity. Saliva (25 $\mu$ l) from the indicated cohorts was analyzed for endogenous C. albicans colonization by plating on yeast peptone dextrose (YPD) agar in triplicate and performing colony enumeration. Data are presented as (A) the percent of each cohort that exhibited any oral colonization or (B) the number of colony-forming units (CFU) in each cohort (Fischer's exact test and Mann-Whitney $U$ test, respectively). (C) Rheumatoid arthritis (RA) subjects exhibit reduced salivary $\beta$-defensin 2 (BD2) levels. BD2 in saliva from the indicated cohorts was determined by enzyme-linked immunosorbent assay (Student's $t$ test). (D) RA subjects show intact salivary candidacidal activity. Salivary Candida killing was determined by centrifuging saliva to remove endogenous microbes and incubating the spun fraction with $10^{6} \mathrm{C}$. albicans (reference strain CAF2-1) for 1 hour at $37^{\circ} \mathrm{C}$. Triplicate samples were plated on YPD for colony enumeration and killing is indicated as the percentage of a PBS control (Student's $t$ test). 


\section{Discussion}

In this study, we found that PBMCs from RA patients showed impaired Candida-induced IL-17A production, despite overall elevated basal IL-17A production and a preserved capacity of $\mathrm{CD}^{+}$cells to differentiate in response to Th17 differentiating cytokines in vitro. The impaired Candida-specific response was associated with an increased rate of RA subjects colonized with Candida as well as reduced expression of BD2, an IL-17A-dependent salivary AMP. Nonetheless, salivary killing activity against Candida was preserved in RA subjects. Thus, while there is clearly a trend towards increased susceptibility to C. albicans colonization in RA, much of the effector antifungal immune response is retained, consistent with the clinical resistance to oropharyngeal candidiasis in RA patients.

Genome-wide association study data point to a role for the Th17/IL-17 axis in RA, as risk alleles impact Th17 generation and maintenance (IL6R, IL2, IL21, TYK2), trafficking (CCR6) or IL-17A signal transduction (TNFAIP3) $[24,25]$. Clinically, active RA has been associated with elevated fractions of Th17 cells compared with healthy controls, and individuals that respond to TNF $\alpha$ inhibitors are reported to show reductions in Th17 cells compared with nonresponders [4]. Erosive arthritis in most animal models is IL-17A dependent, as treatment with blocking antibodies ameliorates disease, and disease induction is mild or absent in IL-17Adeficient mice [26,27]. Hence, agents that inhibit the Th17 pathway at multiple points, including inhibitors of JAK kinases, IL-23, IL-17A and IL-17RA, are currently being used or evaluated in RA and other autoimmune conditions $[9,28]$.

Because the majority of the RA patients in this study had DMARD-controlled disease, we used this group as a reference population. An acknowledged limitation is exclusion of treatment-naïve patients with poorly controlled disease. An ideal follow-up will be to assess longitudinal pathogen-specific responses, starting before drug treatment is initiated. Nonetheless, these findings are internally consistent (reduced Th17 cell frequency, reduced IL-17Aregulated AMP expression, reduced pathogen-induced IL-17A production) and recapitulate the characteristic clinical phenotype of RA, where overt susceptibility to OPC is rarely seen (preserved salivary Candida killing, minimally elevated oral Candida colonization rates). Our findings also suggest there may be a threshold effect of IL-17A in mediating host defense to Candida, where even low amounts of IL-17A are sufficient for protective immunity. Our finding that Th17 cells in RA subjects were reduced relative to controls contrasts with some prior studies, but may be explained by the fact that these patients had controlled disease with an average Disease Activity Score of 3.1 (Table 1).
RA patients generally have not been reported to show a strong susceptibility to $C$. albicans despite their overall increased risk for infections [17]. The reasons for this are unclear, but as only $50 \%$ of patients with Candida esophagitis have concurrent OPC, it is possible (and supported by our data; Figure 3) that RA patients may have elevated rates of subclinical C. albicans colonization, and hence are poised to more readily progress to clinical OPC under certain circumstances; for example, targeted anti-IL-17A therapies. Additionally, innate mechanisms such as salivary killing capacity may help maintain effective immunity to $C$. albicans even in the face of some degree of Th17 depletion (Figure 3). It is unclear whether RA patients also exhibit impaired or altered responses to other Th17-dependent pathogens, such as Staphylococcus aureus or Klebsiella pneumonia, which would be an important line of investigation to stem from these findings.

Traditionally, candidiasis has not been linked to TNF $\alpha$ inhibition, but new data suggest that TNF $\alpha$ inhibitors may in fact increase the risk of OPC [18]. Moreover, joint pathology can be induced or exacerbated by immunization with antigens found in the cell walls of commensal fungi, such as $\beta$-1,3-glucan and zymosan; elevated C. albicans colonization rates such as we observed in Figure 3 thus have the potential to exacerbate RA symptoms [29]. The increased basal IL-17A production in this cohort coupled with impaired C. albicans-induced IL-17A induction (Figure 1A) suggests that patients with RA have elevated IL-17A production on a per-cell basis yet exhibit subclinical pathogen-specific impairments. Accordingly, selective targeting of Th17 pathways may render patients clinically susceptible to OPC or other mucocutaneous manifestations of this fungus. Susceptibility could conceivably be additionally heightened if TNF $\alpha$ inhibitors are used in combination with selective Th17/IL-17 inhibiting agents, since IL-17 synergizes potently with TNF $\alpha[30,31]$.

Although TGF $\beta$, IL-1 $\beta$, IL-6 and IL-23 are important for the lineage commitment and/or function of human Th17 cells, data from animal models suggest that selective exposure to these cytokines during differentiation may differentially impact the function of Th17 cells. Exposure to IL-23 in T cells that were previously polarized by TGF $\beta$ and IL- 6 drives pathogenic Th17 cells, whereas a lack of IL-23 results in IL-10-producing Th17 cells that restrain pathogenic Th17 cells [32,33]. Similarly, the TGF $\beta 3$ isoform induces pathogenic Th17 cells, whereas the TGF $\beta 1$ isoform does not [34]. These data may explain the paradox in RA of having an excessively active Th17/IL17A axis and a simultaneous susceptibility to infections. That is, patients with RA may have elevated pathogenic Th17 cells at the expense of protective Th17 cells. In this regard, the increase in Th1 cells we observed in this study (Figure 2A) suggests that Th1 cells may not compensate for a reduced IL-17 response. This would be consistent 
with both human and animal studies. For example, humans with hyper-IgE syndrome have impaired Th17 levels due to STAT3 mutations; these patients have normal Th1 levels but are nonetheless susceptible to mucocutaneous candidiasis. Similarly, deficient IFN $\gamma^{-1-}$ or IL-12p $35^{-/-}$mice are resistant to oral and dermal candidiasis, whereas $\mathrm{IL}-23^{-/-}$mice and $\mathrm{IL}-17 \mathrm{R}^{-/-}$mice are susceptible [35,36].

\section{Conclusions}

This study finds that patients with RA exhibit impaired C. albicans-specific IL-17A production, despite elevated basal IL-17A serum levels and a preserved capacity for Th17 cell induction in vitro. These impaired responses are associated with an increased rate of oral $C$. albicans colonization and reduced IL-17A-dependent AMP production in saliva. Although mucosal Candida infections are not a commonly reported side effect associated with RA, the present data suggest that biologic drugs selectively targeting the IL-23/IL-17 axis may increase the risk of RA patients to mucosal candidiasis.

\section{Additional file}

Additional file 1: Figure S1. (A) IL-17A production under Th17 differentiating conditions correlates with baseline IL-17A production. IL-17A production by PBMC co-cultures with Th17 differentiating cytokines was correlated to baseline IL-17A production by PBMCs by spearman's coefficient. (B) IL-17 production to HK C. albicans correlates with the fraction of circulating Th17 cells. IL-17A production by PBMCs co-cultured with HK C. albicans was correlated to the fraction of circulating Th17 cells by Spearman's coefficient.

\section{Abbreviations \\ AMP: antimicrobial protein; BD2: $\beta$-defensin 2; DMARD: disease-modifying anti-rheumatic drug; HK: heat-killed; IFNY: interferon gamma; IL: interleukin; OPC: oropharyngeal candidiasis; PBMC: peripheral blood mononuclear cell; RA: rheumatoid arthritis; TGF $\beta$ : transforming growth factor beta; Th: T-helper type; TNF: tumor necrosis factor.}

\section{Competing interests}

SLG has consulted for and received a research grant from Novartis. The remaining authors declare that they have no competing interests.

\section{Authors' contributions}

SB participated in study design, performed cellular immunoassays, performed flow cytometry analysis of peripheral blood lymphocytes, performed candidacidal assays of saliva, performed data analysis and helped to draft the manuscript. EWS performed cellular staining studies and data analysis. ERW and DMJ participated in the preparation and flow cytometry analysis of peripheral blood lymphocytes from RA subjects in the study. KAR helped develop the study database and identified, recruited and collected clinical data and blood samples from RA subjects in the study. MJM participated in study design, helped perform flow cytometry analysis of peripheral blood lymphocytes, performed data analysis and helped draft manuscript. SLG and MCL conceived of the study, participated in study design, performed data analysis and helped to draft the manuscript. All authors read and approved the final manuscript.

\section{Acknowledgments}

SB was supported by T32 DK063922. SLG was supported by the University of Pittsburgh Division of Rheumatology \& Clinical Immunology and National Institutes of Health grants R01 AR054389 and R01 DE022550. MJM was supported by the University of Pittsburgh Division of Rheumatology \& Clinical Immunology. Support for MCL and for data and sample acquisition was provided by National Institutes of Health grant RC2 AR058989 and Genentech, Inc. The content is solely the responsibility of the authors and does not necessarily represent the official views of the National Institutes of Health. Genentech did not have any role in the design, in the collection, analysis, and interpretation of data, in the writing of the manuscript or in the decision to submit the manuscript for publication. Genentech reviewed the manuscript prior to submission and suggested minor edits to improve its readability. The authors thank C Amity and I Metes for assistance with data collection and Dr M Simpson-Abelson for assistance with flow cytometry. The authors thank Dr Larry Moreland and the Rheumatoid Arthritis Comparative Effectiveness Research study group (Antonio Achkar MD, Rohit Aggarwal MD, Noah Bass MD, Alan Berg MD, Sherwood Chetlin MD, Daniel DeLo MD, Robyn Domsic MD, Kenneth Gold MD, Kimberly Liang MD, Douglas Lienesch MD, Kathleen McKinnon DO, Thomas Medsger MD, Niveditha Mohan MD, Chester Oddis MD, Thaddeus Osial, MD, Terence Starz MD, Bertrand Stolzer MD, Elizabeth Young MD).

\section{Author details}

${ }^{1}$ Division of Gastroenterology, Hepatology and Nutrition, Department of Medicine, University of Pittsburgh, Pittsburgh, PA 15261, USA. 'Division of Rheumatology \& Clinical Immunology, Department of Medicine, University of Pittsburgh, BST S702, 3500 Terrace Street, Pittsburgh, PA 15261, USA.

Received: 6 September 2013 Accepted: 15 January 2014 Published: 11 February 2014

\section{References}

1. Mclnnes IB, Schett G: Cytokines in the pathogenesis of rheumatoid arthritis. Nat Rev Immunol 2007, 7:429-442.

2. Gaffen SL: The role of interleukin-17 in the pathogenesis of rheumatoid arthritis. Curr Rheumatol Rep 2009, 11:365-370.

3. Gaffen SL: Structure and signalling in the IL-17 receptor family. Nat Rev Immunol 2009, 9:556-567.

4. Chen DY, Chen YM, Chen HH, Hsieh CW, Lin CC, Lan JL: Increasing levels of circulating Th17 cells and interleukin-17 in rheumatoid arthritis patients with an inadequate response to anti-TNF-alpha therapy. Arthritis Res Ther 2011, 13:R126.

5. Zaba LC, Cardinale I, Gilleaudeau P, Sullivan-Whalen M, Suarez Farinas M, Fuentes-Duculan J, Novitskaya I, Khatcherian A, Bluth MJ, Lowes MA, Krueger $\mathrm{JG}$ : Amelioration of epidermal hyperplasia by TNF inhibition is associated with reduced Th17 responses.J Exp Med 2007, 204:3183-3194.

6. Ni Mhuircheartaigh OM, Matteson EL, Green AB, Crowson CS: Trends in serious infections in rheumatoid arthritis. J Rheumatol 2013, 40:611-616.

7. Listing J, Gerhold K, Zink A: The risk of infections associated with rheumatoid arthritis, with its comorbidity and treatment. Rheumatology (Oxford) 2013, 52:53-61.

8. Hueber W, Patel DD, Dryja T, Wright AM, Koroleva I, Bruin G, Antoni C, Draelos Z, Gold MH, Psoriasis Study Group, Durez P, Tak PP, Gomez-Reino JJ, Rheumatoid Arthritis Study Group, Foster CS, Kim RY, Samson CM, Falk NS, Chu DS, Callanan D, Nguyen QD, Uveitis Study Group, Rose K, Haider A, Di Padova F: Effects of AIN457, a fully human antibody to interleukin-17A, on psoriasis, rheumatoid arthritis, and uveitis. Sci Transl Med 2010, 2:52ra72.

9. Patel DD, Lee DM, Kolbinger F, Antoni C: Effect of IL-17A blockade with secukinumab in autoimmune diseases. Ann Rheum Dis 2013, 72:116-123.

10. Genovese M, Van den Bosch F, Roberson S, Bojin S, Biagini I, Ryan P, Sloan-Lancaster J: LY2439821, a humanized anti-interleukin-17 monoclonal antibody, in the treatment of patients with rheumatoid arthritis. Arthritis Rheum 2010, 62:929-939.

11. Leonardi C, Matheson R, Zachariae C, Cameron G, Li L, Edson-Heredia E, Braun D, Banerjee S: Anti-interleukin-17 monoclonal antibody ixekizumab in chronic plaque psoriasis. N Engl J Med 2012, 366:1190-1199.

12. Papp KA, Leonardi C, Menter A, Ortonne JP, Krueger JG, Kricorian G, Aras G, Li J, Russell CB, Thompson EH, Baumgartner S: Brodalumab, an anti-interleukin-17-receptor antibody for psoriasis. N Engl J Med 2012, 366:1181-1189.

13. Vautier S, Sousa Mda G, Brown GD: C-type lectins, fungi and Th17 responses. Cytokine Growth Factor Rev 2010, 21:405-412. 
14. Acosta-Rodriguez EV, Rivino L, Geginat J, Jarrossay D, Gattorno M, Lanzavecchia A, Sallusto F, Napolitani G: Surface phenotype and antigenic specificity of human interleukin 17-producing T helper memory cells. Nat Immunol 2007, 8:639-646.

15. Huppler AR, Bishu S, Gaffen SL: Mucocutaneous candidiasis: the IL-17 pathway and implications for targeted immunotherapy. Arthritis Res Ther 2012, 14:217.

16. Puel A, Picard C, Cypowyj S, Lilic D, Abel L, Casanova JL: Inborn errors of mucocutaneous immunity to Candida albicans in humans: a role for IL-17 cytokines? Curr Opin Immunol 2010, 22:467-474.

17. Strangfeld A, Listing J: Infection and musculoskeletal conditions: bacterial and opportunistic infections during anti-TNF therapy. Best Pract Res Clin Rheumatol 2006, 20:1181-1195.

18. Ford AC, Peyrin-Biroulet L: Opportunistic infections with anti-tumor necrosis factor-alpha therapy in inflammatory bowel disease: meta-analysis of randomized controlled trials. Am J Gastroenterol 2013, 108:1268-1276.

19. Brown GD, Denning DW, Gow NA, Levitz SM, Netea MG, White TC: Hidden killers: human fungal infections. Sci Trans/ Med 2012, 4:165rv113.

20. Acosta-Rodriguez EV, Napolitani G, Lanzavecchia A, Sallusto F: Interleukins 1 beta and 6 but not transforming growth factor-beta are essential for the differentiation of interleukin 17-producing human $\mathrm{T}$ helper cells. Nat Immunol 2007, 8:942-949.

21. Conti H, Baker O, Freeman A, Jang W, Li R, Holland S, Edgerton M, Gaffen S: New mechanism of oral immunity to mucosal candidiasis in hyper-lgE syndrome. Mucosal Immunol 2011, 4:448-455.

22. Conti HR, Gaffen SL: Host responses to Candida albicans: Th17 cells and mucosal candidiasis. Microbes Infect 2010, 12:518-527.

23. Dongari-Bagtoglou A, Fidel P: The host cytokine responses and protective immunity in oropharyngeal candidiasis. J Dent Res 2005, 84:966-977.

24. Eyre S, Bowes J, Diogo D, Lee A, Barton A, Martin P, Zhernakova A, Stahl E, Viatte S, McAllister K, Amos Cl, Padyukov L, Toes RE, Huizinga TW, Wijmenga C, Trynka G, Franke L, Westra HJ, Alfredsson L, Hu X, Sandor C, de Bakker PI, Davila S, Khor CC, Heng KK, Andrews R, Edkins S, Hunt SE, Langford C, Symmons $D$, et al: High-density genetic mapping identifies new susceptibility loci for rheumatoid arthritis. Nat Genet 2012, 44:1336-1340.

25. Garg A, Ahmed M, Vallejo A, Ma A, Gaffen S: The deubiquitinase A20 mediates feedback inhibition of interleukin-17 receptor signaling. Sci Signal 2013, 6:ra44-ra55.

26. Cornelissen F, van Hamburg JP, Lubberts E: The IL-12/IL-23 axis and its role in Th17 cell development, pathology and plasticity in arthritis. Curr Opin Investig Drugs 2009, 10:452-462.

27. Iwakura $Y$, Ishigame H, Saijo S, Nakae S: Functional specialization of interleukin-17 family members. Immunity 2011, 34:149-162.

28. Miossec P, Kolls JK: Targeting IL-17 and TH17 cells in chronic inflammation. Nat Rev Drug Discov 2012, 11:763-776.

29. Marijnissen RJ, Koenders MI, van de Veerdonk FL, Dulos J, Netea MG, Boots AM, Joosten LA, van den Berg WB: Exposure to Candida albicans polarizes a T-cell driven arthritis model towards Th17 responses, resulting in a more destructive arthritis. PLoS One 2012, 7:e38889.

30. Miossec P: Interleukin-17 in rheumatoid arthritis: if T cells were to contribute to inflammation and destruction through synergy. Arth Rheum 2003, 48:594-601.

31. Shen F, Gaffen SL: Structure-function relationships in the IL-17 receptor: implications for signal transduction and therapy. Cytokine 2008, 41:92-104.

32. McGeachy MJ, Bak-Jensen KS, Chen Y, Tato CM, Blumenschein W, McClanahan T, Cua DJ: TGF-beta and IL-6 drive the production of IL-17 and IL-10 by $T$ cells and restrain $\mathrm{T}(\mathrm{H})-17$ cell-mediated pathology. Nat Immunol 2007, 8:1390-1397.

33. Ghoreschi K, Laurence A, Yang XP, Tato CM, McGeachy MJ, Konkel JE, Ramos HL, Wei L, Davidson TS, Bouladoux N, Grainger JR, Chen Q, Kanno Y, Watford WT, Sun HW, Eberl G, Shevach EM, Belkaid Y, Cua DJ, Chen W, O'Shea JJ: Generation of pathogenic $\mathrm{T}(\mathrm{H}) 17$ cells in the absence of TGF-beta signalling. Nature 2010, 467:967-971.

34. Lee Y, Awasthi A, Yosef N, Quintana FJ, Xiao S, Peters A, Wu C, Kleinewietfeld M, Kunder S, Hafler DA, Sobel RA, Regev A, Kuchroo VK: Induction and molecular signature of pathogenic TH17 cells. Nat Immunol 2012, 13:991-999.

35. Conti HR, Shen F, Nayyar N, Stocum E, Sun JN, Lindemann MJ, Ho AW, Hai JH, Yu JJ, Jung JW, Filler SG, Masso-Welch P, Edgerton M,
Gaffen SL: Th17 cells and IL-17 receptor signaling are essential for mucosal host defense against oral candidiasis. J Exp Med 2009, 206:299-311.

36. Farah C, Hu Y, Riminton S, Ashman R: Distinct roles for interleukin-12p40 and tumour necrosis factor in resistance to oral candidiasis defined by gene targeting. Oral Microbiol Immunol 2006, 21:252-255.

doi:10.1186/ar4480

Cite this article as: Bishu et al:: Rheumatoid arthritis patients exhibit impaired Candida albicans-specific Th17 responses. Arthritis Research \& Therapy 2014 16:R50.

\section{Submit your next manuscript to BioMed Central and take full advantage of:}

- Convenient online submission

- Thorough peer review

- No space constraints or color figure charges

- Immediate publication on acceptance

- Inclusion in PubMed, CAS, Scopus and Google Scholar

- Research which is freely available for redistribution

Submit your manuscript at www.biomedcentral.com/submit
C) BioMed Central 